ARTICLE

\title{
THE NEW AND THE OLD IN THE FILM INDUSTRY: CINEMA, TECHNOLOGY AND NEO-VIEWERS. AN ANTHROPOLOGICAL LOOK AT THE NEW CINEMA.
}

Martínez Oya, Guillem * ${ }^{a}$

a. Independent researcher, Spain.

* Corresponding author (gmartinezoya@gmail.com)

PUBLISHED: 06/07/2021

\section{COPYRIGHT NOTICE:}

\section{CITE THIS PAPER:}

Martínez Oya, Guillem 2021. "The new and the old in the film industry: cinema, technology and neo-viewers. An anthropological look at the new cinema." Journal of Social Sciences: Transformations \& Transitions (JOSSTT) 1(01):02. DOI: https://doi.org/10.52459/josstt3210102

\begin{abstract}
Since its invention, the cinema art and industry has drawn a lot of attention from people of all sectors. It is nowadays a mass phenomenon reaching a very large audience, which has increased even more due to the proliferation of screens resulting from technological advances. As a result, going to the movie theatre has become simply an option among others. This investigation searches into what motivates the current spectator to watch films and the way in which cinema interacts with the viewer, projecting the cinematographic arts beyond the screen. In short, the research characterises the current spectator within the values and the context around him and uses an anthropological methodology to describe how the new spectator lives the cinema and the way in which the old structures and the new ones interact in our hyperconnected world. The main objective of the research is to approach generally the concept of film viewer in our times.
\end{abstract}

\section{KEYWORDS}

Metafilmic, Habitus, Films, Spectator, Hyperscreen, Cinema 


\section{INTRODUCTION}

The present technology has given us a new place as spectators in the culture area. We have a lot of information at our fingertips about anything we want to know: articles, videos, images, exhibitions, places to go, and everything else. Mobile technology empowers the spectator further in his capacity to choose directly what he or she would consume. In the film industry this is both an empowering fact and, at the same time, a weapon in terms of film consumption.

Technology allows us to watch a feature film, a short film or any audiovisual artwork almost anywhere in the world. All we need is a smartphone, an iPad or a laptop with an Internet connection and we can enjoy a large catalogue of films on a wide range of websites, whether paying or not.

The main objective of this research is to study how the spectator approaches the film phenomenon in the context of portable technology, the new economic logics of the film industry and how spectators face the old structures of the film industry. In particular, the emphasis is on how the new spectator, the neo-viewer, 'lives' the films and what their motivations are within today's large film ecosystem to go to the cinema or watch from elsewhere. In short, we will look at what consumption options and behaviour the neo-viewer has today.

Current technology has 'delocalised' the screen as we have known it for some years. Nowadays, you see people consuming all kinds of audiovisual works almost everywhere: in the metro, the bus, the train, in a café, and other places. Most academics claim that this phenomenon is segregating the old cinema as we know it, while others contend that technology actually helps the film industry to expand to places it did not reach before. This continuity of the audiovisual beyond screen space and time is known as hyper-screen.

The concept of 'hyper-screen' was coined by Gilles Lipovetsky and Jean Serroy in 2009. These academics describe it as the proliferation of screens, due to technology, resulting in an extension of the traditional cinema screen, now centred in the viewer, that adds value to what the viewer chooses to watch. According to these authors, this phenomenon does not devalue film as an art form but rather adds to the quality of films through digitisation.

Moreover, this extension of the screen leads to a viewer who is actually educated in the realm of visual arts by the continuous use of the screen in his daily life, as his eyes are more educated than previous generations in visual culture.

In the present world, globalisation has produced a world that is constantly connected in the economic, social, and cultural fields. Film productions are made to circulate globally, and the characteristics of the audience are quite diverse, with many different cultural and social backgrounds. So, the hyper-screen has become a global phenomenon. As a result, a film is today a cultural product that is localised both globally and locally. Thus, we can claim that films are a product embedded in 'glocalisation': a product that moves between global and local logics due to the new technology, new logics of distribution, and the neo-viewer.

The main topic of this article is what motivations the neo-viewer has for choosing one film or another and when and where to watch it. The research aims to understand the new logics between the new and the old structures of the film industry, in order to find out what values the new film productions within the hyper- 
screen environment offer to the neo-viewer, and what values the neo-viewer looks for when watching a film in the cinema, on the screen of his mobile phone, or in his home TV.

\section{THE NEW AND OLD STRUCTURES OF THE FILM INDUSTRY}

\section{A. Glocality: Barcelona and the world}

The film industry, like every industry of today, has three main spheres that are in constant movement and reconfiguration within the internal and external dynamics of the industry. These three spheres are cultural, political and economic.

Cultural synergy refers to the interaction between the local and the global and how differences and equalities interact between the parties involved in the film industry. This cultural synergy becomes apparent, for example, at film festivals and also in any cinema, regardless of the strategic lines of exhibition.

Political synergy moves at the local level of the industry, and its purpose is to act in the global level. Most of the time, political synergies are motivated by global interests, and the film industry is no exception. It is this kind of synergy that shapes, fosters and supports the cinematic arts, at a more localised level, where the global and the local very often meet.

Economic synergy is the most globally driven. In fact, the economic field of the film industry is the most liquid in the contemporary era. This sphere is the most adaptable to the inflows and outflows of the industry and also the most volatile. Its main task is to make film projects viable, particularly by financing film projects. In the economic sphere, as it happens everywhere, the cultural and political spheres have enormous power to modify the viability of a film project.

Specifically in Barcelona, where the writer of this article works, there are two main institutions dedicated to promote the film industry through the three areas mentioned above. The first institution is the Instituto Catalán de las Empresas Culturales (Catalan Institute of Cultural Enterprises), known as ICEC for its acronym in Catalan, and the other is the Academia de Cine Catalán (Catalan Film Academy).

This article centres around these two institutions since they are basic, from an academic and economic perspective, for the formulation of new cultural policies for the film industry according to the present reality. Furthermore, the dialogue between these two institutions within the global film market enables local projects to interact with the glocal levels of the film industry.

The ICEC has a department that works specifically in the audiovisual sector. This department is in charge of supporting film projects and professionalising them in the fields of production, distribution and exhibition, including particular films, festivals or any type of project within the audiovisual field.

The main objective of the ICEC is to influence the Catalan market and to launch projects outside of it in order to interact in the global sphere and with the other structures within the industry.

The main competencies of the Audiovisual Department of the ICEC are governed by the state policies of the central government. This is because the ICEC is a governmental institution linked to the Generalitat de Catalunya and reports directly to the central government of Spain. 
The Audiovisual Department is also in charge of coordinating the Catalunya Film Commission, whose main objective is to promote and coordinate film projects in the Catalan territories. This department also has a direct relationship with the Catalan Films \& TV Foundation, whose main objective is to externalise film projects on a global scale.

The Catalan Film Academy has a more academic character. This institution is a foundation financed by the Generalitat de Catalunya and private patrons whose main objective is to promote the artistic and scientific projects of the cinematographic arts in the Catalan territories and to offer a unified vision of Catalan film companies.

Specifically, the Catalan Film Academy promotes new artistic movements in cinematographic creation, for their projection at the national, European, and global levels. In addition, this foundation has a political purpose related with governmental institutions, through promoting and consolidating filmmaking, in order to make it more competitive.

While these two institutions are fundamental for film companies, we cannot forget the enormous ecosystem of film companies in Catalonia and in Spain that influences the actions and policies of the ICEC and the Catalan Film Academy. Here, we should mention the vertical and horizontal breakdown of the sector, initiated in the 1970s, which has created a variety of companies in the field of audiovisual works and which we can see reunited, more or less as a single voice, in the actions of the ICEC and the Catalan Film Academy.

At the national level, the Instituto de la Cinematografía y de las Artes Audiovisuales (Institute of Cinematography and Audiovisual Arts), known as ICAA by its Spanish acronym, is an independent agency within the Ministry of Education, Culture and Sports of the Spanish Government. Its main purpose is the planning of policies for the film and audiovisual sector in the three main processes of the industry: production, distribution and exhibition. In general, it aims to promote audiovisual works made in Spain.

The ICAA works together with the Instituto de Crédito Oficial (Institute of Official Credit), known as the ICO for its Spanish acronym, whose main objective is the creation of credit or compatible-credit lines, for the founding of films and other audiovisual projects.

Due to the economic and financial crisis of 2008, the law of the film industry in Spain was modified. In particular, we should mention within the scope of this article that the new law (cited as law 55/2007) defines, among others, the terms 'exhibitor', 'distributor' and 'producer', with the qualification of 'independent' but makes no mention of the term 'spectator'.

This lack of definition of 'spectator' within this context shows a lack of interest in the viewer on the legal side: who the viewer really is, and what he/she wants. Obviously, this lack of information leads to a lack of understanding, and the presently existing need to know the interests and motivations of the viewer.

\section{B. How we interact with images in films: a look at the viewer's motivations and interests.}

The cinematographic images in a film, together by the sound that composes the audiovisual artwork, are both a maker and a mirror of social clichés related to the viewers, showing the social and aesthetic excellence or decadence of, and in front of, the viewers. 
The interaction with the audiovisual screen and with the image itself follows two schemes: two parts of a process that present the spectator with the filmic concept and the metafilmic concepts involved.

The first scheme in the logic of the spectator is the "principle of association of ideas". This principle concerns the images displayed in movement on the screen. Ansón (2012), who conceptualises this term, refers to this principle as the relationship between the concepts exposed in the film, as connected to each other by differences or similarities.

The second scheme is called "the first and second identification in the film". This corresponds to the logic of the viewer and how the viewer extrapolates concepts and ideas. Specifically, the first identification is the empathetic or antipathetic correspondence that rises between the spectator and the screen. The second identification is the way the viewer extrapolates the concepts expressed on the screen from his or her own cultural and social background to the film itself.

Thus, film images comprise a value in themselves whenever they have a 'use' for the viewer. A use that the viewer incorporates in his or her own cultural, social, educational, and economic framework.

It is definitely a kind of correspondence or intimate distance between the viewer and the image on the screen that creates a dialogue and shows how we interact with the film. It is this very correspondence that creates the motivations and interests in the viewer towards the film, who shapes them according to his or her economic, social, cultural, and educational background.

\section{The era of the glocal screen: towards the age of the hyper-screen}

Within the current context of glocality - the rapid interactions between the global and the local- the film arts industry is no exception. In fact, it is one of the most glocalised industries in the world due to multiple factors such as the new liquid business models, the disintegration of the vertical business model into a more horizontal one, and the new technologies that surround us which make the audiovisual product one of the most important and versatile in today's world.

The context described above has reconceptualised the term 'cinema', mainly because of the need to highlight the old, classic screen among the others existing today.

Today, we understand a cinema as a space that follows a business strategy of expansion, where a group of people go in a process of collective projection of an audiovisual work, which is usually imaginary, and is appreciated for its aesthetic and auditory quality.

Due to the current proliferation of screens, this reconceptualisation of cinemas does not diminish the value of films. As Lipovetsky and Serroy (2009) contend, the proliferation of screens is actually an extension of cinemas. The screen is not devalued by this phenomenon but remains the same for the spectator - only with a more advanced technology. In short, the experience of going to the cinema is better.

The very expansion of the screen has changed the value that the spectator puts in watching a film in a cinema or on other screens. So, the added value of the film itself is the only thing that has changed, since excellence in the film is one important motivation for enjoying the film in a cinema or on any other screen.

Another motivation for the spectator to go to the cinema is in the concept of the "spectator as crowd" developed by Alvarado Duque in his 2011 article, 'Las mutaciones del espectador. El cine como estética de la 
multitud' (The mutations of the spectator. Cinema as the aesthetics of the multitude). Alvarado Duque describes the concept as a collective moment in a dark and secluded space where all people remain silent and are joined by the power of the screen, which segregates them as individuals but, at the same time, unites them as a crowd in a relationship of the spectacularity of the screen and the images projected on it.

Due to the revaluation of cinemas and the extension of the screen - known as the hyper-screen - new parameters in film genres are redefined from the old ones. This has reconfigured both the spectator's willingness to watch films and the industry's approach. This is a phenomenon that Lipovetsky and Serroy (2009) have conceptualised as 'global focus'.

With this 'global focus' in the film industry and new technologies multiplying the screen around us, current and future generations are more literate in audiovisual culture. This is simply because of the intense use of the screen in our daily lives, which directly affects how we interact with images and sounds. It was Alvarado Duque, in his aforementioned article of 2011, who coined the term of neo-viewer.

The neo-viewer belongs to those generations that have grown up with a diversity of audiovisual products, in an environment where the screen is naturalised due to everyday use.

In this view, the economic interest of the film industry is guided by cultural, socio-aesthetic, transpolitical and anthropological contexts. These contexts are redefining how the audiovisual product interacts in a glocal way.

The cultural context is implied in the exhibition process because of the cultural background where the audiovisual product is projected and, specifically, the cultural background of the neo-viewer.

The socio-aesthetic context interacts more directly with the neo-viewer through the appreciation of the images exhibited in the film, which appeal to the aesthetic appreciation of the viewer and his/her social and cultural lifestyle.

The transpolitical context is the interaction between film and politics, specifically, the use of films by governments as a powerful transmitter of ideas and concepts amongst the population. Film images are both proposed to and assimilated by the reality around us. A fact that can be of political interest.

The anthropological context is mentioned given the capacity of the film to influence the transpolitical, socio-aesthetic and cultural context of the environment where it is shown and the behaviour of people. In this way, film is seen as a phenomenon of change.

All together, these contexts interact with the economic interest of the film, in a complex of synergies constantly readjusting commercial logic around the production, distribution and exhibition processes, and provoking a constant readjustment of the spectator in relation with the extension of the screen, the glocal film industry and the neo-viewer.

\section{Tastes in Film: A New Perspective from Bourdieu}

There is nothing written about tastes. Or almost, because Pierre Bourdieu wrote about them in 'La distinction. Critique social du jugement' (The distinction. A social critique of judgement). The French sociologist, through an extensive empirical study carried out in the 1960s, classified tastes into 3 groups, all determined by people's social origin and cultural background. 
The first group described by Bourdieu is that of 'legitimate taste', defined by a high educational level which is directly related to the upper classes. The second group is described as 'average taste' and is related to people who are relatively educated and belong to the middle classes. The third and last group is the 'popular taste', and Bourdieu refers to it as the taste corresponding to the lower classes which are characterised by a low cultural level.

Although Bourdieu's classification of tastes is outdated today, there are several points that are still valid in our cultural and social context. This is due to new logics in the economic, social and cultural environment that have changed the old classification of economic classes in Northern countries and so have blurred the old scheme.

Derived from Bourdieu's old classification of tastes, these are described as an individual expression, in a social context, of the differences that delimit a lifestyle, which at the same time defines the acceptance of some cultural and social practices and rejects others as being consistent or not with the modus vivendi that one wants to project in society.

This is what Bourdieu conceptualised as 'habitus'. The 'habitus' is a system that generates practices that are both concretised and produced, at the same time, in the individual, and help him or her to project the meanings of lifestyles in the social context, leading to a social and cultural reproduction of practices in the various social spaces.

Habitus, so, is directly related to cinema because of the power of the cinematic experience to influence or discourage certain practices and customs in the neo-viewer, and the ability of the neo-viewer to portray that cinematic experience in his or her everyday life: to define a 'lifestyle'. This is the metafilmic aspect, including how the current viewer relates to it.

At this point, we will use an ethnographic point of view in our research methodology for the data collection and observation of reality. This methodology allows us to delve deeper into the motivations of the current viewer and his or her social and cultural context.

In short, the main idea that Bourdieu brings is how the cinematic experience has the capacity to show lifestyles that are extrapolated by the spectator, by defining his or her own lifestyle beyond the screen through reconfiguring it.

\section{E. The neo-viewer as the centre of the Seventh Art}

As mentioned above, the image requires a person or a team to produce it and someone willing to see it in order for it to be meaningful, whatever its meaning may be. It is in this perspective that the spectator is one of the most powerful structures for the image and for cinema itself.

By spectator we mean a person who attends a public spectacle. This definition sustains the 'presence' of the spectator but not the implication of what it means to 'be there', as British social anthropologists termed at the beginning of the 20th century.

The reformulation of the concept is strictly necessary to understand what the concept of 'spectator' means today and how he or she interacts in front of the cinema screen. Considering the current context in which technology, the relocation of the screen, Bourdieu's structures of taste and the type of relationship with 
cinema, the new spectator - the neo-spectator or neo-viewer - is one who attends a spectacle, whether public or not, and participates in it either consciously or unconsciously.

Behind this reformulation of the concept of the neo-viewer, which takes into account the 'principle of association of ideas', the images on the screen have a social and psychological power in themselves, in so far as they express something in agreement or disagreement with the viewer that influences his or her semiotic field. This is where the filmic and the metafilmic converge.

This same semiotic field, which is lived in a private or public space sharing the image through the screen, makes the neo-spectator feel the cinema as an individual experience that is lived collectively. It is necessary to refer to the context in which the film is seen because it directly influences the appreciation of the images by the new spectator. Therefore, two people can watch the same film in different places and, due to the cultural and social background of each one and the screen they use to watch, their appreciation can be quite different.

Thus, there are two main levels to film images. The first is the inherent power of the image in filmic movement. The second is the viewer's response to it on the semiotic, cultural, and social levels.

The dominance of the cinema screen among other screens confers a more spectacular power to the former. The cinema screen has a relationship with the spectator defined by the difference in the filmic fact, making the experience of going to the cinema truly spectacular, in the sense described by Guy Debord.

It is also important to understand the fluctuations and constant readaptation of the spectator and the film industry. This readaptation takes place especially on the exhibition due to the various channels existing today, such as Video On Demand, Arthouses, Film Festivals and so on.

The semiotic fields of the new spectator derived from the original filmic context are extrapolated to the metafilmic, and result in a social relation based on the distinction of tastes. This relation of distinction has an auxiliary component on the aesthetic disposition of the viewer. That is to say, the way we show ourselves in society and our social and cultural practices show our ideal selves. And this determines, in turn, the film consumption by individuals (Ariño, et al, 2006).

\section{TALKING TO THE NEO-VIEWER: AN ETHNOGRAPHIC APPROACH}

Our main objective here is to know what are the motivations of the neo-viewer to select a film and a particular screen. The main technique used in this research is the ethnographic method, which allows us to go deeper into the subject of research through the use of qualitative techniques and quantitative indicators.

A small survey was made with participants from the area of Barcelona, taking into account their social origin, economic class, gender identification, age and social condition as well as level of education, which is mentioned in the Table 1.

For this preliminary research, six people were selected, and sessions were held consisting of watching a film and talking about the filmic and the metafilmic aspects explained above. The talks had a duration of a few hours, and the interviews were open with some preliminary questions. 
As a social and cultural anthropologist, I included myself among the subjects of the research because 'being there' changes the view of the participating individuals by modifying their behaviours and performances.

Table 1: Author's own research, 2018.

\begin{tabular}{|c|c|c|c|c|c|}
\hline NAME & AGE & GENDER & EDUCATION & JOB & BIRTHPLACE \\
\hline Spectator A & $\begin{array}{c}27 \text { years } \\
\text { old }\end{array}$ & female & $\begin{array}{l}\text { Higher Degree in } \\
\text { Ephemeral Space Design } \\
\text { (Cultural sector) }\end{array}$ & Does not work & $\begin{array}{c}\text { Sant Pere } \\
\text { Pescador. Middle } \\
\text { class. Catalan }\end{array}$ \\
\hline Spectator B & $\begin{array}{l}28 \text { years } \\
\text { old }\end{array}$ & female & $\begin{array}{l}\text { Postgraduate in } \\
\text { International } \\
\text { Cooperation }\end{array}$ & $\begin{array}{l}\text { Manager of a } \\
\text { performing arts } \\
\text { company }\end{array}$ & $\begin{array}{l}\text { Olot. Lower- } \\
\text { Middle class. } \\
\text { Catalan. }\end{array}$ \\
\hline Spectator C & $\begin{array}{c}60 \text { years } \\
\text { old }\end{array}$ & female & $\begin{array}{l}\text { Degree in Economics } \\
\text { and in Social and } \\
\text { Cultural Anthropology }\end{array}$ & $\begin{array}{c}\text { Cultural } \\
\text { mediator and } \\
\text { photographer }\end{array}$ & $\begin{array}{l}\text { Barcelona. Upper } \\
\text { class. Catalan. }\end{array}$ \\
\hline Spectator D & $\begin{array}{c}56 \text { years } \\
\text { old }\end{array}$ & male & High School Diploma & Taxi driver & $\begin{array}{l}\text { Barcelona. } \\
\text { Lower-Middle } \\
\text { class. Catalan. }\end{array}$ \\
\hline Spectator E & $\begin{array}{l}18 \text { years } \\
\text { old }\end{array}$ & male & High School Diploma & Store assistant & $\begin{array}{l}\text { Sant Joan Despí. } \\
\text { Lower class. } \\
\text { Catalan. }\end{array}$ \\
\hline Spectator F & $\begin{array}{c}20 \text { years } \\
\text { old }\end{array}$ & male & Engineering student & $\begin{array}{l}\text { Delivery man in } \\
\text { U.P.S. }\end{array}$ & $\begin{array}{l}\text { Sant Joan Despí. } \\
\text { Lower class. } \\
\text { Catalan. }\end{array}$ \\
\hline Spectator G & $\begin{array}{c}39 \text { years } \\
\text { old }\end{array}$ & male & Degree in Fine Arts & $\begin{array}{l}\text { Company } \\
\text { coordinator }\end{array}$ & $\begin{array}{c}\text { Sant Pere de } \\
\text { Ribes. Lower } \\
\text { class. Colombian. }\end{array}$ \\
\hline Spectator $\mathrm{H}$ & $\begin{array}{c}31 \text { years } \\
\text { old }\end{array}$ & female & $\begin{array}{l}\text { Degree in Social } \\
\text { Education }\end{array}$ & $\begin{array}{l}\text { Social Educator } \\
\text { in a foundation } \\
\text { for disable } \\
\text { people }\end{array}$ & $\begin{array}{l}\text { Sant Pere de } \\
\text { Ribes. Lower } \\
\text { class. Catalan. }\end{array}$ \\
\hline Researcher & $\begin{array}{l}27 \text { years } \\
\text { old }\end{array}$ & male & $\begin{array}{c}\text { Master|்̃ Degree in Arts } \\
\text { Management }\end{array}$ & $\begin{array}{l}\text { Communicator, } \\
\text { Cultural } \\
\text { Journalist and } \\
\text { Researcher }\end{array}$ & $\begin{array}{l}\text { Barcelona. Lower } \\
\text { class. Catalan. }\end{array}$ \\
\hline
\end{tabular}

The following comments were made after watching the film 'Hard Candy'. This film was released in 2005 and directed by David Slade. The film told the story of a teenage girl who meets a man in an internet 
chat room. One day, they go on a date to get to know each other and then head to the man's house. There, the teenager tries to convince the man to confess to a paedophile offence he committed some time ago. The circumstances elaborated by the teenager make the man confess to the crime and end up committing suicide in case his ex-wife finds out.

After watching 'Hard Candy', the participants in the research showed generally an assimilation of the main character - the teenager-. Therefore, empathy for a fictional fact assimilated as "true" situates the neoviewer within the fiction they are watching.

It is important here to take into account the centrality of the narrative through the film image, as this is what generates in the spectator the "principle of association of ideas" and the subsequent empathy or antipathy with the characters and the narrative of the film.

A reflection that showed up in the talks is how the film is able to create situations that go beyond itself and are reflected in the neo-viewer, and how the audience is able to transfer these fictional situations to their everyday life.

The metafilmic aspects go beyond the audiovisual work itself. This is something that the new spectator approaches through the 'second identification in cinema', which is an extrapolation of the filmic narrative of the film and its characters into the social, cultural and everyday context of the spectator, who either "accepts" or "rejects" those various situations as he or she reflects on them.

Another aspect observed during the fieldwork with the group interviews is the genre preferences of the films. These preferences are directly related to the cultural and social practices of the neo-viewer. In particular, the production and reproduction of certain lifestyles to express the differences between individuals living in contemporary society is a really important factor in determining the choice of film genre.

A mention should be made here to the social background of one of the participants who had a complicated family relationship that affected her view of the film situation. Also, this complicated family relationship directly affects the kind of cinema she likes to watch because cinema is a kind of abstraction: a kind of dream.

As to the film genre preferences, it is also necessary to mention the relation between the hyper screen and the participants born in 1990. These participants grew up in an environment where the screen was becoming increasingly more present. A situation that makes the power of the visual more significant, naturalising the participants' relationship with the screen and with the audiovisual and making them more accustomed to audiovisual works. So, filmic preferences are directly conditioned by each individual's own life trajectory, their cultural practices and the naturalisation of the screen by the neo-viewer.

We can see the metafilmic dimension by talking to the research subjects about who they would recommend 'Hard Candy' to. Here, the semiotic field in the viewer is really important, because they seek to compare the narrative of the film, and also the image, with other films in order to express the similarity of the concepts expressed. This is influenced by the viewer's abstraction and conceptualisation provoked by previous films. This is the "principle of association of ideas" at work. 
An important point to highlight is the spectator's appreciation of the relationship to other arts. Curiously, cinema is an art capable of reproducing itself in other films, but usually it does not transcend other arts through the viewer's schema.

During the group interviews, the subjects did not relate the cinematic arts to other arts. The neo-viewer focuses his or her gaze on the film image in a socio-aesthetic way but does not relate the film directly to other arts. Instead, the neo-spectator fixes his or her gaze on the visual harmony and instructive logics within the film itself, looking only for a "real" image in the audiovisual work and for its images to be "naturalised".

When asked for what features did catch their attention in the film, the participants referred to the performance of the main actress, her aesthetics and the cinematography. In other words, the viewer makes direct reference to the film itself, but without transcending the power of the image and sound. The conversation, centred on the main actress and her aesthetics, directly influences both the performances and their values.

Through the conversations with the research subjects, it was clear that films are not only a cultural and leisure product, but a visual phenomenon capable of provoking a dialogue: a film is a space for dialogue where individuals can expose, beyond the hyper-screen, their cultural, political and anthropological synergies.

These synergies are important for the reconstruction of the film by the spectators. It so happened that some individuals constructed the image from a male perspective. Specifically, two women made reference to the fact that the image in the screen was constructed from a male perspective. Both women conjectured about what that same film would be like if it were directed by a woman.

Another point addressed during the research was who the viewer goes to the cinema with and what their motivations are for going with one person or another. Viewers only pondered on this issue when asked, but not spontaneously in their daily lives. There are two variables here that directly influence the new viewer in selecting the people he or she wants to go to the cinema with. The first is the narrative and the second is the image itself. Both are determining factors in choosing with whom to go to the cinema.

Besides these two variables there are others that influence the semiotic and psychological mind of the spectator to choose his or her cinema companions. The first is the concept, already explained, of "the spectator as crowd": sharing a collective moment, such as watching a film at a public screen does not preclude the fact that this is also an individual moment because of the correspondence between the spectator and the companion through the screen narrative. The second concept that influences the choice of the film companion is the screen room, a space where a group of people, known or unknown to each other, share a collective screen process. Again, at the centre is the spectator, who is the audience involved in a "public" but also an individually experienced spectacle.

Another interesting issue is the narration within the audiovisual product. This is one of the fundamental bases for connecting with the spectators and making the audiovisual work. This definitely situates the viewer and helps him or her connect the visual, the sound and the metafilmic. During the interviews, it was clear that the viewer's eye is educated to be focused on the audiovisual story without being noticed and so, the neo-spectator is focused through the figure of the film's narrator. 
Emphasising the image, the viewer fixes his or her point of view to recreate, according to his or her cultural, social, and economic synergies, the lifestyles of the characters in the films. Viewers elaborate this analysis of the characters from a recreation of some social clichés appreciated in the image they are watching on the screen, and this is where the visual and narrative filmic discourse dialogues with the cultural background of the viewers.

Consequently, the viewer identifies him or herself with his or her own gaze, and experiences this representation as a fundamental object that transcends the film.

When discussing the ending of the film 'Hard Candy', we could see a divergence between the filmic and the metafilmic in the spectator. Here, transpolitical synergies take shape to define the concept of justice in the context of the film's ending and what justice is, in its everydayness, for the viewer. Furthermore, during the interview with the research subjects, the viewers were apt to change their minds about these concepts due to the narrative of the film and the talk afterwards.

There was a current thought, elicited by the film, about whether the end justifies the means. Here we can see the transpolitical and anthropological synergies and we can also find the principle of association of ideas and primary identification. We see the first concept flow in the empathic or antipathic relationship between the spectator and the visual in the film and the way the spectator extrapolates the narrative. The second derives from the centralisation of the spectator as the main object in the audiovisual work and the way in which this very centralisation forces the spectator to transcend the filmic.

Important as it is for the neo-viewer to know the film crew behind the audiovisual work and the process of its creation, it is most important to know the director of the project and the director's lifestyle. This is paramount for the new viewer because the film project and the director's lifestyle are strictly linked. Still, in some exceptional cases, the viewer is able to separate the creator from the person but, what is important here, is that the person who has created the film is strictly related to his or her personal life just like a "brand". The filmmaker is, today, a brand with his or her own cinematic style.

With reference to the ending of the film, none of the interviewed were able to connect the last scene to the folktale Little Red Riding Hood when confronted with it. Instead, they made a connection between the ending of the film and the context in which the film was made: contemporaneity. Here we see again the principle of association of ideas: relating the ending of the film to the present context. In other words, this principle works within the cultural synergy of the spectators as the parameter where the audiovisual product is developed and shown.

Ultimately, the research showed that there are three main important characteristics in the neo-viewer that motivate them to experience the seventh art.

The first is the understanding of the audiovisual product as something filmic, in the sense that the spectator appreciates the contents of the audiovisual work where the main object is the story, and inside this, the central 'subject' that dialogues with the spectator. Likewise, the new spectator creates this dialogue influenced by the 'first identification', which is how he identifies his own gaze with the representation made in the filmic story, and uses the principle of association of ideas to relate this representation to his own visions, finally creating a dialogue with the audiovisual work and his thoughts and ideals. 
The second feature goes beyond the film: the metafilmic, as a derivative part of the first characteristic. In the new spectator, the 'first identification' leads to what is conceptualised as the 'second identification', where the spectator identifies him or herself with the internal narrative of the film: the actions, the performances and the articulation. The articulation of the narrative where he or she extrapolate the contents of the film with their own lives and lifestyles. Narrative articulation, which is the main object of the metafilmic, is the result of the 'relations of distinction' that express the way we show ourselves in society through our cultural and social practices and ideals in a comparative relation to the film, either unconsciously or consciously.

The third and last characteristic, generated by the other two, is the capacity of the film to generate in the neo-viewer a system of physical and mental practices that configure a semiotic world within their current context.

\section{THE NEO-SPECTATOR IN BARCELONA: A BRIEF SYNTHESIS}

As we have seen, the concept of spectator in the audiovisual industry has changed due to the liquid society in which we live (in the sense that Bauman gives to the term, and which has been widely accepted). This article addresses the reconfiguration of the concept of spectator in the face of the new needs of the film industry and the new needs of the spectator himself.

Thus, an important part of the new behaviour of the neo-viewer is due to the rapid changes in technology strictly related to the digitisation prices of audiovisual works. In particular, the growing number of screens that allow access to films are causing a delocalisation of films and moving the viewer to other spaces and other times: the hyper-screen. The growing number of screens with new VoD technologies and platforms, such as YouTube for example, has changed the old cinema system into a new multi-platform system.

Still, the cinema screen does not suffer a discredit by the new viewer. The original screen has reconfigured its value and extended the audiovisual work beyond the cinema space. One of the most significant aspects of this is the glocalisation of the audiovisual product, which has adapted to new local and global strategies, resulting in a new economic logic that is constantly being recycled. Think, for a moment, of Netflix. A video-on-demand platform that produces series and films released globally but, at the same time, also produces specifically for each country where the VoD platform is present.

As a result, viewers have changed their movie-watching preferences, which changes their appreciation of the Seventh Art and its metafilmic. These preferences are the result of the multiple uses of the screens around us, setting us emphatically into audiovisual culture.

Another characteristic of the neo-viewer is his or her relationship with the film as based on narrative. The narrative is the main connection and is an empathetic or antipathetic safeguard before the contents of the film. Moreover, this connection enables the semiotic field in the spectator beyond the film: a really important feature for the new spectator, namely the metafilmic component.

This metafilmic component generates lifestyles that are captured by the spectator who can accept or reject them according to his or her cultural and social practices. Ergo, the metafilmic enables the principle of 
association of ideas, inducing in the neo-spectator concrete cultural and social practices that, at the same time, create semiotic schemas in his or her life.

The same semiotic schema described above, but acting in reverse, describes the viewer's decisions about the choice of film genre, due to the predilections of cultural and social practices in the film and in the viewers themselves.

In itself, a film is an audiovisual product that transcends the screen. This fact forces the viewer to look for something transcendental that is assimilated to his or her own reality or, at least, is comprehensible even if he or she does not share it. In the view of Guy Debord (2010), cinema presents us with the spectacle while, at the same time, it represents and induces it in the people who watch it, who then re-present it in the same field -i.e., cinema- or other fields.

As a result of his or her interest in the metafilmic, the spectator develops an interest in the creative process of the audiovisual work and what it entails, making the Seventh Art reproduce and assimilate itself, turning self-referential for the most part.

As for the image itself, there are two fundamental characteristics for the viewer: that it is pleasing to the eye, and that it shows a certain naturalness. That is to say, it reflects "reality" as close as possible, or at least gives a credible fiction for the viewer.

As for the sound, it simply becomes natural in the film, because the spectator does not attach importance to it if it is not linked to an image. Therefore, the auditory part is in the background, not because of its lack of importance, but because it is seen as inserted in the visual.

It should be noted the importance that the spectator acquires in film events because, ultimately, he or she is placed at the centre because he or she is the final figure in the film production process. For the industry and the political and academic institutions related to the cinematic arts, this is absolutely important, however a characterisation of the figure of the spectator as a primary entity is missing in the industry's vocabulary.

In conclusion, the main motivations for the new spectator - the neo-viewer, in this research- to watching one audiovisual product or another are: the story as a primary entity, the individual and personal correspondence with the story, the metafilmic that he or she is able to discern, the transcendence of the film in his/her everyday life, and the position that the audiovisual work occupy within the semiotic field of the neoviewer.

Not to be dismissed is the important fact that the entities that make up the industry and the academy lack a definition of the new spectator as one of the main agents involved in this art. Therefore, as this research shows, it is vitally important to define the concept of spectator and adapt it to the new social, cultural, political, and economic logics of our time. 
FUNDING: The author did not receive any external funding.

CONFLICT OF INTEREST: The author declares no conflicts of interest.

ACKNOWLEDGMENT: The author expresses his special thanks of gratitude to the reviewer/editor(s) who have dedicated their considerable time and expertise to the journal's rigorous editorial process regarding to improving process of the manuscript to be acceptable for publication by the journal.

\section{REFERENCES}

- Alvarado Duque, C. F., (2011). Las mutaciones del espectador. El cine como estética de la multitud. Comunicación, (28), 59-72. Retrieved from

- ANSÓN, A. (2012) "El cine y sus espectadores. Aproximación al descubrimiento del cine por los escritores franceses". MOENIA. 18. 499-510 pp. [Online] URL: https://revistas.usc.gal/index.php/moenia/article/view/816

- $\quad$ ARIÑO, Antonio; Castelló, Rafael; Hernández, Gil Manuel; Llopis, Ramón (2006) La participación cultural en España. Madrid. Fundación Autor. ISBN: 978-84-8048-716-0.

- BOURDIEU, P. (1998) La distinción. Criterios y bases sociales del gusto. Madrid. Ediciones Santillana. ISBN 84-306-0338-7. [Online]

URL: https://www.academia.edu/7384950/Pierre_Bourdieu_La_distinci\%C3\%B3n_Criterio $\mathrm{y}$ bases sociales del gusto

- DEBORD, G. (2010) La sociedad del espectáculo. Valencia. Pre-Textos. ISBN: 978-848191-442-9.

- Law 55/2007 (Ley 55/2007) del Cine, 28 de Diciembre. Boletín Oficial del Estado. Madrid, 29.12.2007. No. 312.

- LIPOVETSKY, G; SERROY, J. (2009) La pantalla global. Cultura mediática y cine en la era hipermoderna. Barcelona. Editorial Anagrama. ISBN978-84-339-6290-4. 